\title{
3- $\phi$ Multi-Pulse Ac To Dc Converter Through Zig Zag Transformer
}

\author{
Amarendra Pandey, Rakesh Narvey and Praveen Bansal \\ Department of Electrical Engineering \\ MITS, Gwalior \\ amarendra8109@Gmail.Com
}

\begin{abstract}
This paper deals with the reduction of Total Harmonic Distortion (THD) by using Multi-pulse AC to DC Conversion technique. The three-phase multi-pulse AC to DC conversion system have a phase-shifting transformer and a three-phase source. Every such type of converter provides a 6-pulse AC to DC conversion system, that's why in order to produce more sets of 6-pulse systems, a uniform phase-shift is required and hence with proper phase-shifting angle, 12, 18, 24, 30, 36 and higher pulse systems have been produced. The performance improvement of multi-pulse converter is achieved for total harmonics distortion (THD) in supply current, DC voltage ripples and form factor. This paper presents the discussion of multi-pulse improved power quality ac-dc converter (IPQC) configuration, comparative factors and selection of specific.
\end{abstract}

Keywords: Multipulse conversion technique, 18-pulse converter, 24-pulse converter, THD, output waveforms

\section{Introduction}

In the past few years a lot of work has been done for the reduction of Total Harmonic Distortion using different concepts and applications. As we know that nowadays there are so many non-sinusoidal load due to these loads a lots of harmonics contents are produced and these harmonics contents are affect the distribution system to solve these problems and meet the international standard for power quality we need some technique. Multipulse technique is one of technique for these non-sinusoidal load. The problem of poor power quality is an occurrence defined as a nonstandard current, voltage or frequency that results in the failure or mall operation of the end user equipment. All the distribution networks, critical commercial and sensitive industrial loads suffer from number of outages and the service is interrupted which costs a significant financial loss to the distribution companies and industries. Therefore maintaining the quality of the supply provided to the consumers and various loads up to the standards, is a very important and critical task. For providing the required dc supply three-phase ac-dc converters are widely used in adjustable-speed drives (ASDs), HVDC systems, uninterruptible power supplies (UPSs), solar photovoltaic systems (PVs), battery energy storage systems (BESSs) etc., also for battery charging in the electric vehicles, and as power supplies for

Telecommunication systems [1-8]. Traditionally ac-dc converter are used for this purpose that is also known as rectifier which convert alternating into direct current are produced by using thyristors and diodes for supplying the controlled and un controlled power flow in both unidirectional and bidirectional dc power. Rectifiers have the disadvantage of poor power quality as in terms of the injected current harmonics, poor power factor at input ac supply and voltage distortion and the rippled dc output at load due to these reasons a new devices are used in construction of rectifiers which are selfcommutated like as MOSFETs ,IGBTs etc. These converters are classified as power- 
factor corrector (PFCs), pulse width modulation (PWM) rectifiers, multi-pulse rectifiers, multilevel rectifiers etc. This paper is divided into eight sections.

\section{Objective of Present Study}

The present study is an effort towards analyzing the different multi-pulse AC to DC converters in solving the harmonic problem in a three-phase converter system. The effect of increasing the number of pulses on the performance of AC to DC converters has been analyzed. For performance comparison the major factors considered are the ripple percentage, form factor and the total harmonic distortion (THD) [9].

\section{Multi Pulse Methods}

With the help of multi pulse method the harmonics contents in ac-dc converter is reduced because of multiple converter used in circuit that's why harmonics produced by one converter is cancelled by harmonics produced by another converter. Due to this some specified harmonics related to number of converters are eliminated from the power source. In multi-pulse converters, reduction of AC input current harmonics is important as regards to the impact the converter has on the power system [10]. Multi-pulse methods are characterized by the use of multiple converters or multiple semiconductor devices with a common load Figure 1 and Figure 2 given below depict the various techniques used widely for the reduction of harmonics [11].

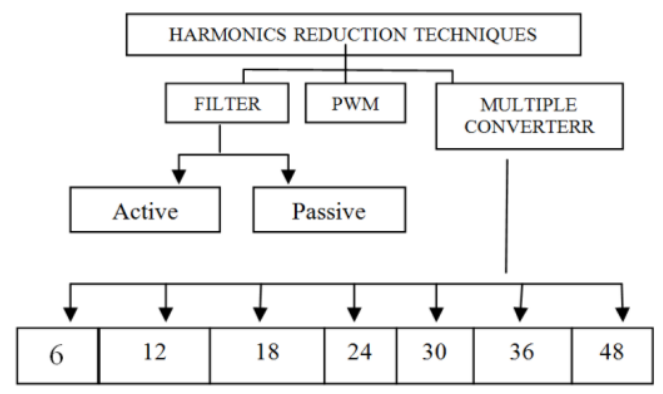

Figure 1. Various Harmonics Reduction Techniques

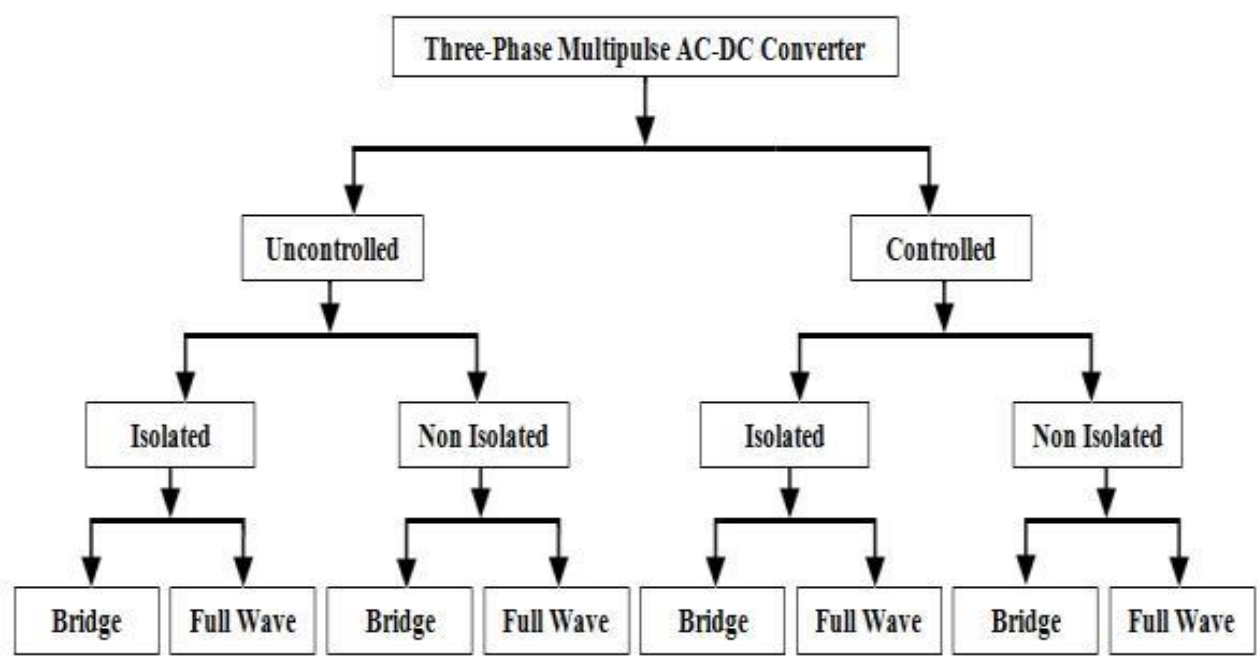

Figure 2. Multi-pulse Converter Configuration 
For the ease \& convenience model \& FFT analysis for RL load only, have been provided in the adjoining text.

\section{Multi-pulse Converter}

There are two type of pulse converter according to controlling techniques first one uncontrolled and second one is controlled multi-pulse converter. Uncontrolled multi-pulse has fixed output and controlled multi-pulse converter has controlled output which can control by the firing angle ' $\alpha$ '.

There are various multi-pulse converters which classified according to number of pulse.

Let us suppose that the number of pulse is ' $\mathrm{m}$ ' Fo is output frequency and Fs is supply frequency

$$
\text { Fo }=m F s
$$

and length of pulse also depend on number of pulse

$$
\text { pulse length }=2 * \mathrm{pi} / \mathrm{m}(\mathrm{in} \mathrm{rad})
$$

\section{A. Eighteen pulse rectifier}

The 18-pulse rectifier topology consists of a multi-phase transformer and three 6-pulse diode bridges. In the theoretical 18-pulse system, the three phase-shifted voltage sources connected to the three 6-diode bridges will cancel the 5th , 7th ,11th , and 13th harmonics and the remaining dominant harmonic components are the 17 th and $19^{\text {th }}$ [13]. The multiphase transformer can be an autotransformer or a phase-shifting isolation transformer with $20^{\circ}$ displacement used to provide three three-phase voltage sources that cancel the 5 th , 7 th , 11th , and 13th harmonics A phase shift of $20^{\circ}$ has been provided between all three phase shift transformers with star connected secondary [12].

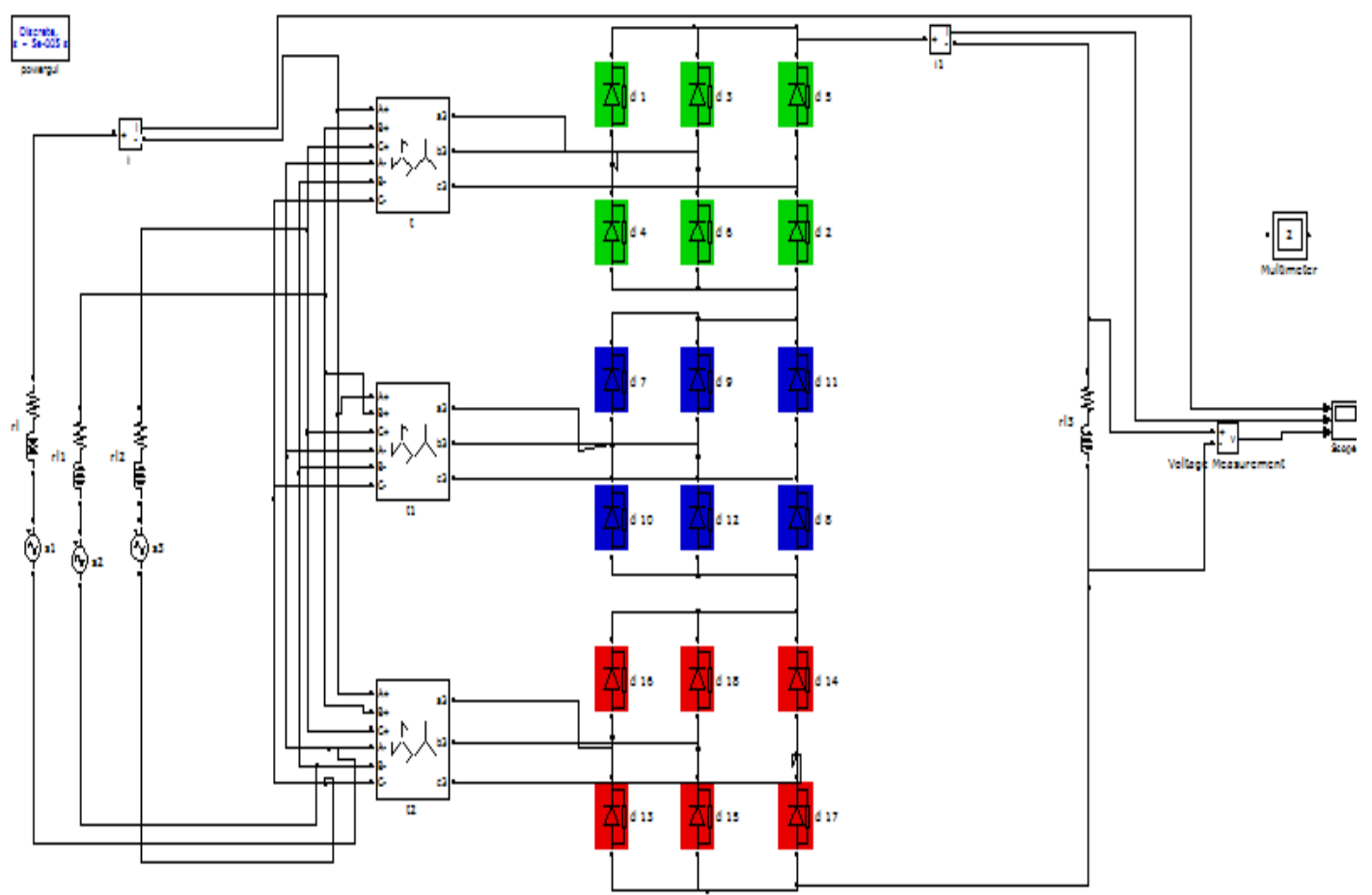

Figure 3. Eighteen Pulse Converter 


\section{B. Twenty Four Pulse Converter}

The connection for 24-pulse converter and the corresponding connections are shown in Figure 9. Four six pulse converters phase shifted by 15 degrees from each other, can provide twenty four pulse rectification, obviously with much lower harmonics on AC and DC side. Its AC output voltage would have $24 \mathrm{n} \pm 1$ order harmonics i.e., $23 \mathrm{rd}, 25 \mathrm{th}, 47 \mathrm{th}$, 49th harmonics with magnitudes of $1 / 23 \mathrm{rd}, 1 / 25 \mathrm{th}, 1 / 47 \mathrm{th}, 1 / 49 \mathrm{th}, \ldots$ respectively, of the phase shift.

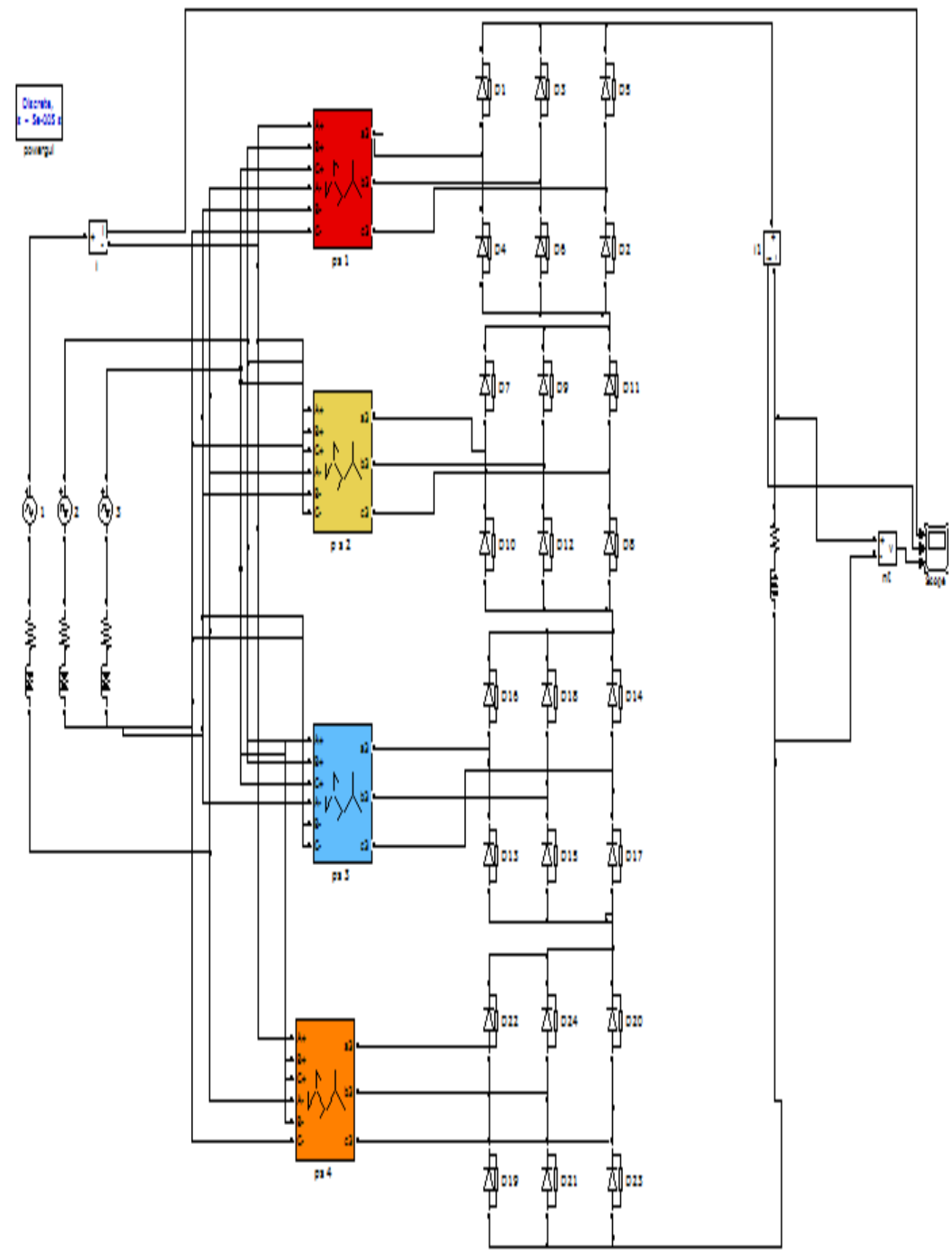

Figure 4. Twenty Four Pulse Converter 


\section{Result and Discussion}

The simulated result and its output waveform are shown in figure bellow

A. OUTPUT WAVEFORM OF EIGHTEEN PULSE CONVERTER

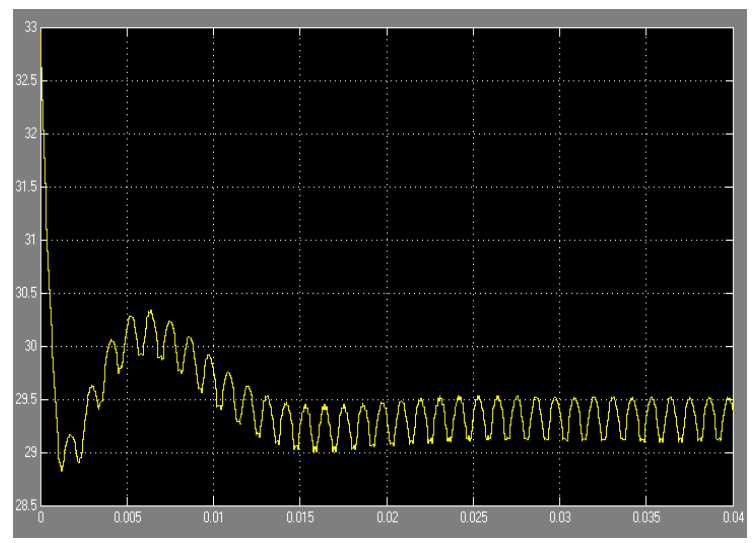

Figure 5. Output Voltage Waveform

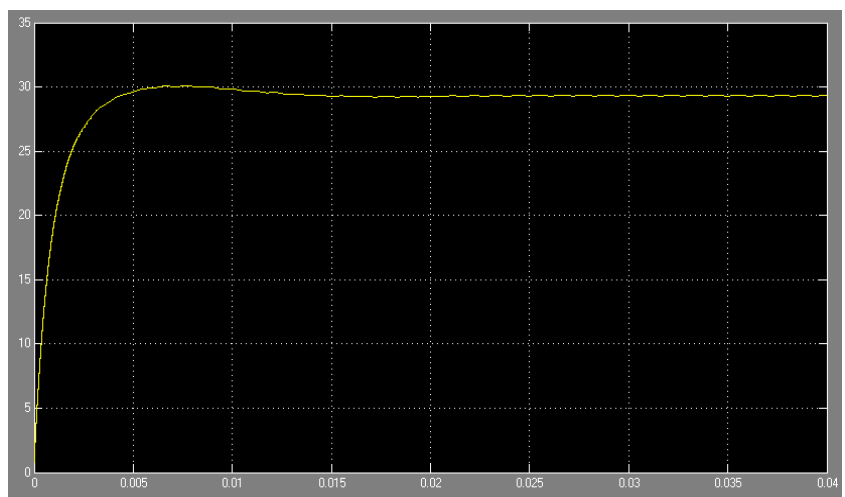

Figure 6. Output Current Waveform

Output waveform of twenty-four pulse converter

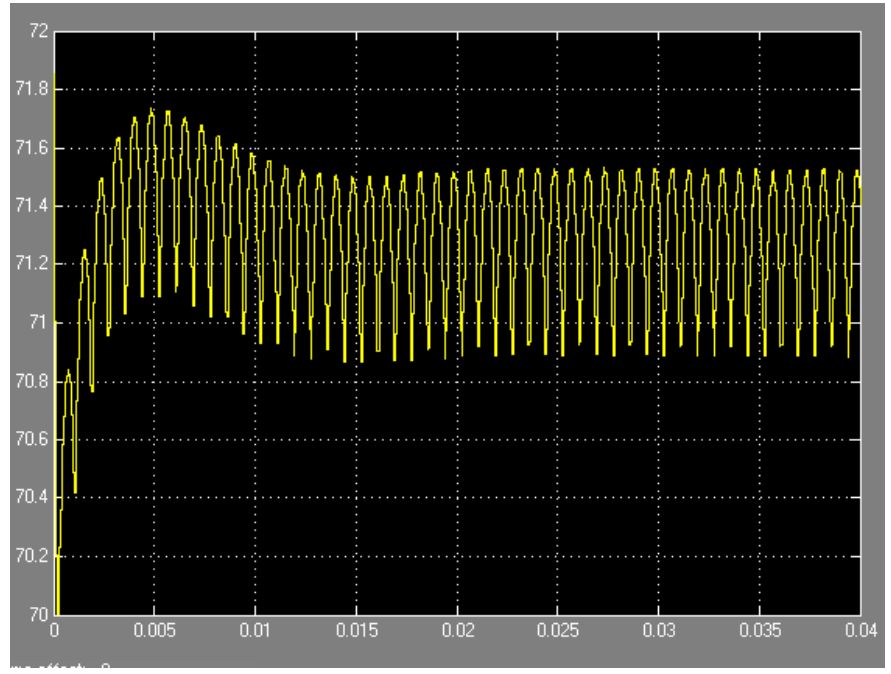

Figure 7. Output Voltage Waveform 


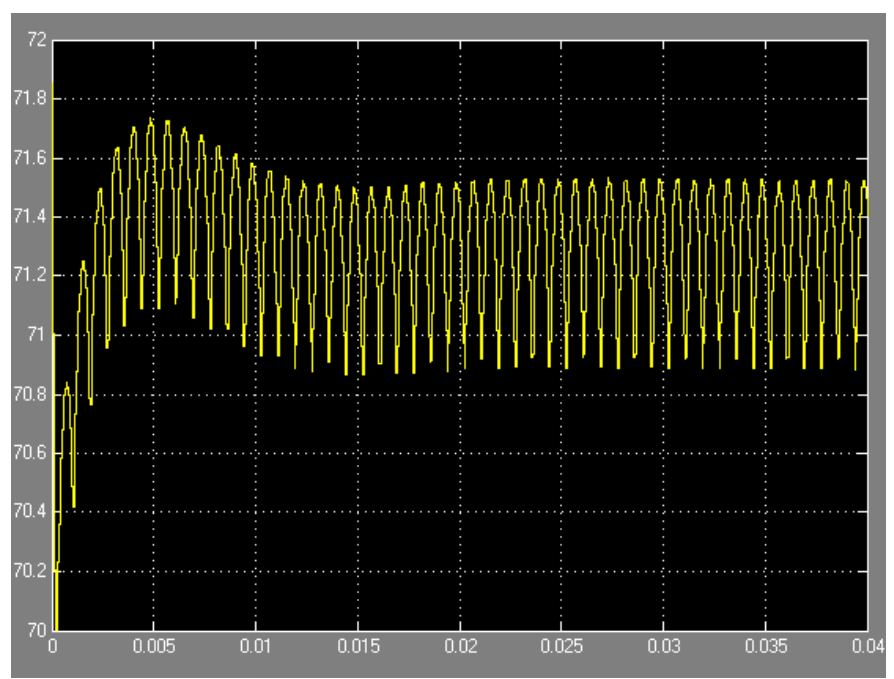

Figure 8. Output Current Waveform

B. THD AND FFT ANALYSSIS OF EIGHTEEN PULSE

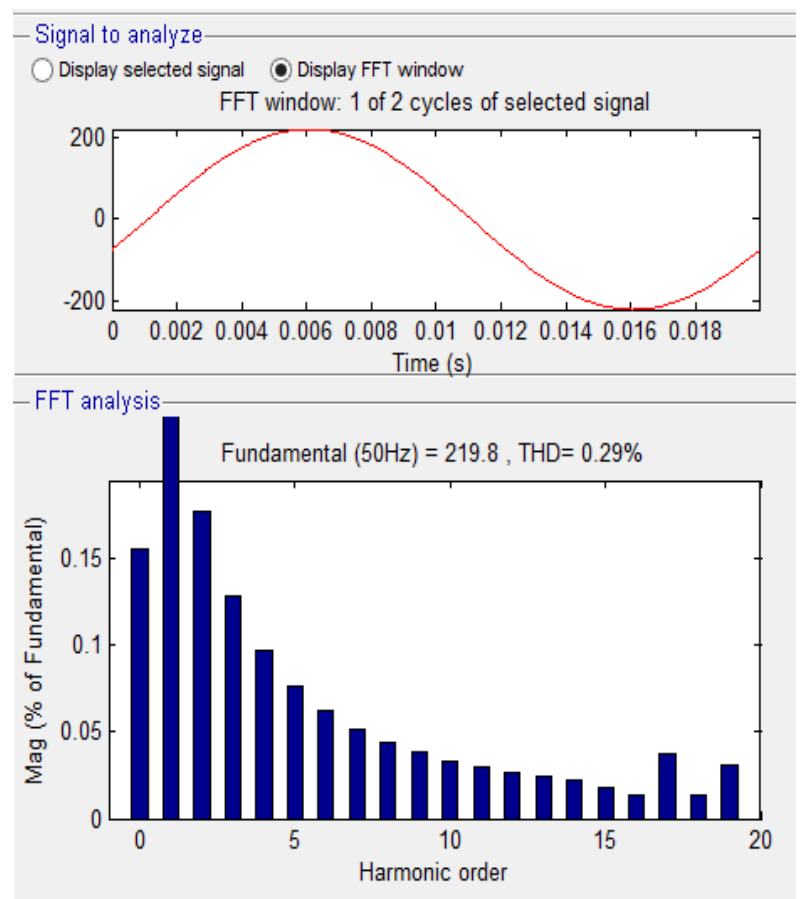

Figure 9. THD Analysis 


\section{THD AND FFT ANALYSIS OF TWINTY FOUR PULSE CONVERTER}

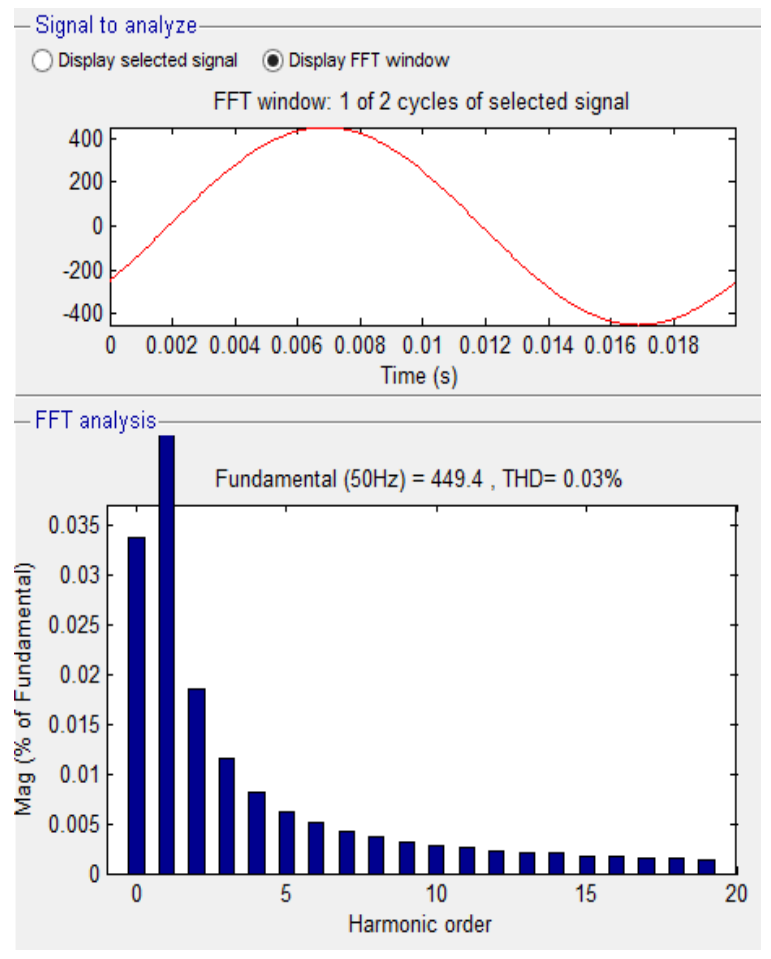

Figure 9. THD Analysis Twenty-four Pulse

\section{Component Selection of IPQCS}

For the high level performance of ac-dc converters the selection of the components of IPQCs is very important. The main and expansive component of IPQCs is the solid-state devices. For low power rating converters, MOSFETs are generally utilized, resulting in high efficiency at high switching frequency. For medium power rating converters IGBTs are used due to their good gating characteristics and wide range of switching frequency for balanced switching losses and size of filter components. For high power rating converters GTOs are normally used. These converters have the advantages of selfcommutation and ability of reverse voltage blocking. Thyristors and diodes are employed in multi-pulse converters. Number of power devices in one module along with the protection and gating system makes the IPQCs small in size and lighter in weight. Other components are the energy storage systems as inductors, capacitors used in filters and protection systems.

In these converters transformers operating at low frequency are used in multi-pulse converters. In multi-pulse converters the size, weight and rating are the important components of the transformer.

\section{Selection of IPQCS for Specific Application}

Selecting any IPQCs for any specific application is an important decision to make. Some important factors for selecting the right converter for any specific application is:

- Power quality level required (allowed THD, PF, DF);

- Type of dc voltage required as output;

- Power flow required (unidirectional or bidirectional);

- Number of operating quadrants (one, two or four);

- Power quality required of the output (ripple, sag and swell);

- Type of load (nonlinear, linear etc.); 
- Cost, weight and size;

- Rating ;

- Reliability in operation;

These are some of the important factors to be considered for selection of IPQCs for any specific application

\section{Conclusion}

A comparative review for the three-phase multi-pulse IPQCs has been done to discover a broad perspective on different configurations of ac-dc converters. The discussed IPQCs can be considered to be the better alternatives for power quality improvement because of the reduced size of the converter, lower cost and higher efficiency as compared to other methods of power quality improvement.

\section{References}

[1] W. M. Grady, M. J. Samotyj and A. H. Noyola, "Survey of active power line conditioning methodologies", IEEE Trans. Power Delivery, (1990) July, pp.1536-1542.

[2] R. Ridley, "Three-phase power factor correction circuits-part 1," in Proc. HFPC'94, (1994), pp. 278321.

[3] D. Borojevic, "Analog vs. digital design three-phase powerfactor correction-Part 2," in Proc. HFPC'94, (1994), pp. 322-348.

[4] H. Akagi, "New trends in active filters for power conditioning", IEEE Trans. Ind. Applicat., vol. 32, (1996) November/December, pp. 1312-1322.

[5] B. Singh, K. A. K. Al. Haddad, and A. Chandra, "A review of active filters for power quality improvement," IEEE Trans. Ind. Electron., vol. 46, (1999) October, pp. 960-971.

[6] M. El-Habrouk, M. K. Darwish, and P. Mehta, "Active power filters: a review Applicat., vol. 147, (2000) September, pp. 493-413.

[7] G. Seguier, "Power Electronic Converters AC/DC Conversion”, New York: McGraw Hill, (1986).

[8] G. T. Heydt, "Electric Power Quality", 2nd ed. West Lafayette, IN: Stars in a circle, (1994).

[9] D. A. Paice, "Power Electronic Converter Harmonics -Multi-pulse method".

[10] B. Singh, S. Gairola, B. N. Singh, A. Chandra, and K. A. Haddad, "Multi- pulse AC-DC Converter for Improving Power Quality: A Review" IEEE. Transactions, On Power Delivery, vol. 23, no.1 (2008) January.

[11] G. K. Dubey, S. R. Doradla, A. Joshi and R. M. K. Sinha, “Thyristorised Power Controllers”, New Age International publisher, (1996), July.

[12] D. Singh, H. Mahala, P. Kaur, "Modeling \& Simulation of Multi-Pulse Converter for Harmonics Reduction", ISSN-SEP-2012.

[13] J.-K. Kang, "Multi-Pulse Rectifier Solution for Input Harmonics Mitigation", Yaskawa Electric America (2005). 